\title{
Potential application of recycled plastic materials as a replacement for polyurethane wheels
}

\author{
B. Thomas, S. Martinez \& M. Hadfield \\ Sustainable Design Research Centre, Bournemouth University, UK
}

\begin{abstract}
Polyurethane (PU) has been the primary material used in skateboard wheels since the 1970s. Since then PU wheels have been used on a wide range of scooters, trolleys and other applications. Polyurethane wheels offer a smoother ride, better grip with the pavement and improved abrasion resistance compared to previous wheel materials. However, the polyurethane used for these wheels cannot be easily recycled and with the dwindling resources and ever increasing laws governing waste recycling, maintenance of resources has become increasingly important. This makes it necessary to find new uses for recycled plastics, apart from the typical low-grade uses such as packaging and road filler that result from the uncertain material properties of recycled plastics. The friction and wear of recycled plastics are often less affected by the recycling process than other material properties; consequently it is decided to study the potential application of recycled plastic materials to replace polyurethane wheels. A range of common recycled plastics are selected. These materials are then examined using a modified Plint TE57 reciprocating tribometer in sliding over an asphalt surface, using these results to analyse their friction and wear performance compared to polyurethane. A new test rig design is developed and varied contact conditions are tested. Data obtained from the tests shows that recycled polycarbonate could be a suitable replacement for polyurethane in this case with similar friction and wear results detected. Sustainability considerations regarding the use of recycled plastics are also analysed, demonstrating the advantages of the use of recycled plastics to the environment, these include reducing the $\mathrm{CO}_{2}$ footprint by over $50 \%$, the embedded energy consumed by $40 \%$ per wheel, and the economic material cost by $67 \%$, among other benefits.

Keywords: tribology, friction, recycled plastics, polyurethane, skate wheels.
\end{abstract}




\section{Introduction}

This paper outlines initial testing towards the potential use of recycled plastic materials to replace Polyurethane wheels, specifically those used on skateboards. This focus is developed as it is seen that the recycling of plastics can result in a wide variability on material properties due to contaminants, shortening polymer chain length etc., however the deterioration of mechanical properties is far less pronounced when looking at tribological properties such as friction and wear this leads to the possibility of focusing on these for future use of recycled plastics. One potential application within this field is in Polyurethane (PU) wheels, as used on skateboards, scooters, roller skates and similar applications.

\subsection{Background to research - skateboard wheels}

As the sport of roller skating increased in popularity during the 1960 s the early metal or wooden wheels [2] began to be replaced by wheels formed from a composite of clay, plastic, walnut shells, paper and polymer binding agents [3]. These wheels exhibited a smoother ride and better traction than the steel wheels used previously, but still lacked the grip needed to prevent rider injury [4]. In addition, the wheels would wear rapidly on outdoor concrete surfaces and were extremely vulnerable to uneven ground, largely restricting them to indoor use [2]. As the 60 s went on the increasing popularity of roller skating, and the newly invented variation of skate boarding led to consumer pressure for a simple, high grip wheel to allow both sports to develop beyond a hobby. It was not until 1973 that the first polyurethane wheel purposely designed for the skateboard went into production and helped turn skateboarding into the popular sport that it is today. Polyurethane wheels offered a smooth ride and high friction, hugely increasing the popularity of skateboarding. Moreover, they showed good wear performance, offering high load capacity and abrasion resistance [2-5].

Nowadays, polyurethane continues to be the primary material used in the manufacture of skateboard wheels [6] offering a wide range of options in terms of their hardness, diameter, shape and colour [7]. Typically large, soft wheels are used for long, cruising boards and hard, small wheels are used for skate park boards and tricks. It is towards these harder wheels that the potential for recycled plastics is thought to be greatest. There are multiple sizes of wheels used, each one appropriate for a particular skate activity. Wheel sizes vary from 48$66+\mathrm{mm}$, although typically range from 52-60mm [8]. Skateboards wheel hardness is measured using the ASTM D2240 type A scale (e.g. a wheels hardness would be given as '99A'). Nevertheless, some manufacturers have started to use the type D scale to classify wheels which are harder than 100A [9-10]. Other manufacturers refer to these harder wheels as 101A hardness, which technically does not exist, since the shore durometer scale only goes from 0 to 100 . Typically soft wheels would range from $80-90 \mathrm{~A}$, with hard wheels at 95-'101'A. 


\subsection{Plastic recycling summary}

Since the end of the $19^{\text {th }}$ century plastic materials have been used to replace all kind of materials in applications where their use was inconceivable not too long ago [11]. The key factor for the success of plastics is the ability to modify their properties to different applications needs [12]. With the increase in consumer good consumption, the quantity of household waste has become a huge issue for local economies. Plastics are now one of the most prevalent materials in the domestic waste stream, and their low biodegradeability and good potential for recycling present a compelling argument for its priority in closing the waste loop [13-14]. Increasing legislation and landfill costs [15] have exacerbated the problem, it is estimated that currently the UK uses 5 million+ tonnes of plastics each year, of which just $25 \%$ is expected to be recycled or recovered [16].

Other drivers towards the reuse of plastics include resource preservation, plastics represent $\sim 4 \%$ of global oil consumption, and with increasing resource scarcity this cost is likely to increase [14]. One of the main problems of plastic recycling is that when a plastic is recycled its mechanical properties often deteriorate (or become unpredictable), for this reason recycled plastics tend to be used in less demanding applications than the original virgin material [1]. Recycled plastics are used in automobiles, packaging and construction [17] often for form or filler effects where performance demands are not as high as in other applications.

\section{Materials selection}

\subsection{Existing wheel analysis}

Samples of new and used hard wheels are obtained from a local skateboard shop [18]. These are rated at between 97A and 99A hardness, of similar diameter and width, and exhibit from new to fairly heavy wear.

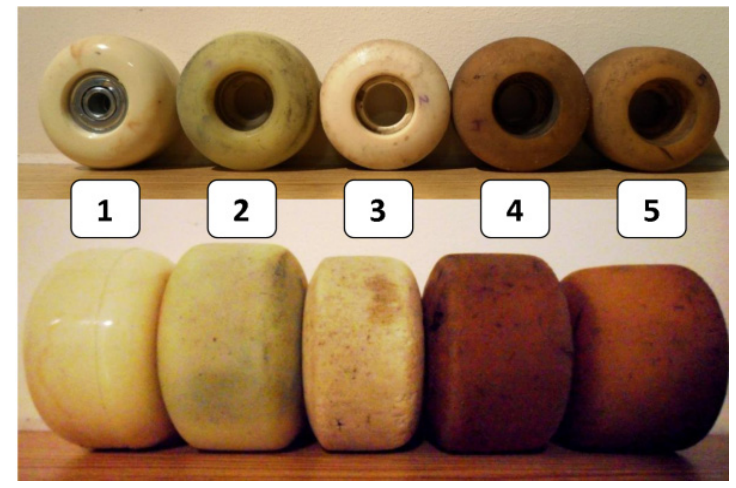

Figure 1: $\quad$ View of the five analysed wheels. 


\subsection{Surface scan using ZYGO and later analysis}

Surface analysis of the wheels is performed using a Zygo inferometer. The graph below indicates that the original smooth surface of a new wheel (e.g. wheel \#1) rapidly degrades, with the roughness of the lightly used wheel \#2 approaching that of the other heavily worn wheels.

\subsection{Selection of test plastics}

The recycled plastics to be tested are selected using the criteria below:

- Material properties: materials chosen for the study should have properties as similar as possible to polyurethane, especially in terms of their friction/wear, Young's modulus, density, hardness, Poisson's ratio etc.

- Facility to obtain/abundance: The candidate plastics must be present in the waste stream and affordable.

An initial search using the CES materials database [25] shows three clear candidates based on the mechanical properties and abundance in the waste stream, High Density Polyethylene, Polypropylene, and Polycarbonate. A summary of materials properties is shown in table 1 below:

Table 1: $\quad$ Potential candidate materials properties.

\begin{tabular}{|c|c|c|c|c|c|c|c|c|c|}
\hline & \multicolumn{3}{|c|}{ Density $\left(\mathrm{kg} / \mathbf{m}^{3}\right)$} & \multicolumn{3}{c|}{ Young's Mod. (GPa) } & \multicolumn{3}{c|}{ Poisson's ratio } \\
\hline PU & $1.04 \times 10^{3}$ & - & $1.06 \times 10^{3}$ & 4.09 & - & 4.3 & 0.375 & - & 0.391 \\
\hline HDPE & 952 & - & 965 & 1.07 & - & 1.09 & 0.41 & - & 0.427 \\
\hline PP & 897 & - & 906 & 1.18 & - & 1.41 & 0.402 & - & 0.41 \\
\hline PC & $1.14 \times 10^{3}$ & - & $1.18 \times 10^{3}$ & 2.21 & - & 2.4 & 0.392 & - & 0.408 \\
\hline
\end{tabular}

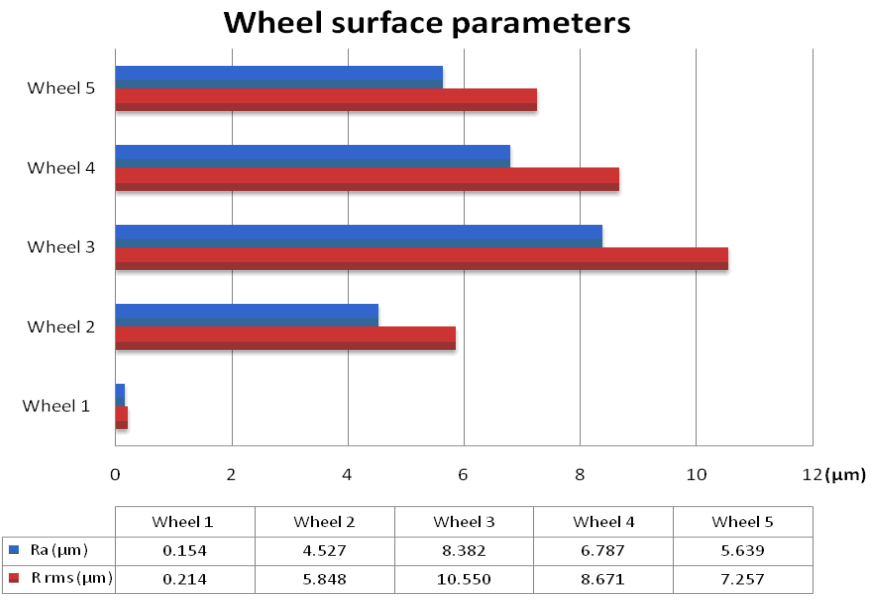

Figure 2: $\quad$ Measured values of Ra and Rrms for the different wheels analysed.

Samples of recycled plastics are provided by CK Polymers Ltd, who specialise on the supply of commercial quantities of recycled plastics. In each 
case, two grades of material are tested, an injection grade (inj.) and an extrusion grade (ext.), these each exhibit different Melt Flow Indexes (MFI).

\section{Experimental work}

A series of screening tests are performed to ascertain the potential for recycled plastics to replace PU in skateboard wheels. The tests measure wear and friction against a typical asphalt surface at the expected contact pressures and velocities. Tests are designed to investigate the friction and wear of the plastic materials at the point of slip - i.e. when the wheel starts to skid. This forms the primary performance criteria for the rider as it specifies the minimum turn radius that can be achieved without the wheel skidding. Before designing the tests, it is necessary to determine the wear processes present in real-world conditions, and to determine test parameters such as contact pressure, speed, etc. [19].

\subsection{Selection of test machine}

A modified Plint TE57 reciprocating tribometer is used to perform the tests. The TE57 reciprocating tribometer consists of a sample mounted in a reciprocating arm which moves against a fixed pin [20]. An electric motor actuates the reciprocating arm, for which the stroke can be manually set between 1 and $5 \mathrm{~mm}$. A maximum load of $50 \mathrm{~N}$ is applied using a spring-lever arrangement while the frequency is computer controlled up to $25 \mathrm{~Hz}$. A piezo-electric transducer measures the friction force, sending the signal to the data acquisition software.

\subsection{Experiments}

Two series of tests are run; firstly an initial series of friction tests to ascertain the friction performance of the materials tested against an asphalt sample. Following these tests, the best performing materials are subject to a series of extended wear tests to determine their wear resistance in relation to the PU wheels.

\subsubsection{Design of reciprocating sliding test rig}

A test rig geometry using a $10 \mathrm{~mm}$ dia. cylindrical pin is developed. When running tests with a flat-ended pin as in this case, the alignment between the pin and sample can be crucial. In this case the pin is designed with a conical upper section to allow it to self-level under loading [21].

\subsubsection{Reciprocating friction test parameter calculation}

It is decided to test the materials at frequencies of $5 \mathrm{~Hz}$ and $20 \mathrm{~Hz}$, which combined with the $5 \mathrm{~mm}$ stroke equates to sliding speeds of 0.05 and $0.2 \mathrm{~m} / \mathrm{s}$ respectively. It is believed that the first situation would simulate a normal turn at a regular speed and large radius of curvature, while the second one simulates a hard-fast turn, in which the wheels slide quickly over the pavement due to high speed and/or a small radius of curvature. Contact loads for the tests are set to 10, 20,30 and $40 \mathrm{~N}$, which corresponds to $0.127-0.509 \mathrm{MPa}$ contact pressure. The 
contact force applied is limited to $40 \mathrm{~N}$, to reduce temperature build-up at the contact when operating with higher values of contact force and frequency.

\subsection{Tests methodology}

\subsubsection{Sliding Friction tests methodology}

Initially a series of short friction tests are run testing the different materials against the asphalt surface. The tests are run for 5 minutes each, in order to obtain stable friction force (steady-state sliding). The test schedule below is developed:

Table 2: $\quad$ Friction tests at $5 \mathrm{~Hz}$.

\begin{tabular}{|c|c|c|c|c|c|}
\hline \multirow{2}{*}{ MATERIAL } & \multirow{2}{*}{$\begin{array}{c}\text { Frequency } \\
(\mathbf{H z})\end{array}$} & \multicolumn{4}{|c|}{ CONTACT FORCE } \\
\cline { 3 - 5 } & $\mathbf{5}$ & $\mathbf{1 0} \mathbf{N}$ & $\mathbf{2 0} \mathbf{N}$ & $\mathbf{3 0} \mathbf{~}$ & $\mathbf{4 0} \mathbf{~}$ \\
\hline PU - Wheel 2 & $\mathbf{5}$ & F5 & F2 & F3 & F4 \\
\hline PU - Wheel 5 & $\mathbf{5}$ & F9 & F10 & F7 & F8 \\
\hline HDPE ext & $\mathbf{5}$ & F13 & F14 & F11 & F12 \\
\hline HDPE inj & $\mathbf{5}$ & F17 & F18 & F19 & F20 \\
\hline PC MFI 11.2 g & $\mathbf{5}$ & F21 & F22 & F23 & F24 \\
\hline PC MFI 32 g & $\mathbf{5}$ & F25 & F26 & F27 & F28 \\
\hline PP ext & $\mathbf{5}$ & F29 & F30 & F31 & F32 \\
\hline PP inj & & &
\end{tabular}

Table 3: $\quad$ Frictions tests at $20 \mathrm{~Hz}$.

\begin{tabular}{|c|c|c|c|c|}
\hline \multirow{2}{*}{ MATERIAL } & \multirow{2}{*}{$\begin{array}{c}\text { Frequency } \\
(\mathbf{H z})\end{array}$} & \multicolumn{3}{|c|}{ CONTACT FORCE } \\
\hline & & $10 \mathrm{~N}$ & $20 \mathrm{~N}$ & $30 \mathrm{~N}$ \\
\hline PU - Wheel 2 & 20 & F33 & F34 & F35 \\
\hline PU - Wheel 5 & 20 & F36 & F37 & F38 \\
\hline HDPE ext & 20 & F39 & F40 & F41 \\
\hline HDPE inj & 20 & F42 & F43 & F44 \\
\hline PC MFI $11.2 \mathrm{~g}$ & 20 & F45 & F46 & F47 \\
\hline PC MFI $32 \mathrm{~g}$ & 20 & F48 & F49 & F50 \\
\hline PP ext & 20 & F51 & F52 & F53 \\
\hline PP inj & 20 & F54 & F55 & F56 \\
\hline
\end{tabular}

\subsection{Wear tests methodology}

Following the initial friction tests, a second series of wear tests are carried out on the materials exhibiting friction values closest to the original PU wheels.

\subsubsection{Sliding wear tests methodology}

The sliding wear tests are run over 12 hours and for two different conditions of contact force and sliding speeds. This allows appreciable wear to develop.

The two cases simulated are at $5 \mathrm{~Hz}$ with a $20 \mathrm{~N}$ contact load, and at $10 \mathrm{~Hz}$ frequency with a $30 \mathrm{~N}$ contact load. These frequencies, with the $5 \mathrm{~mm}$ stroke in the tribometer and the 12 hours test duration, give a total sliding distance of 2160 and $4320 \mathrm{~m}$ respectively. The 20 and $30 \mathrm{~N}$ contact forces equate to contact pressures of $0.25 \mathrm{MPa}$ and $0.4 \mathrm{MPa}$. The initial friction tests indicated that the 
Table 4: $\quad$ Sliding wear tests.

\begin{tabular}{|c|c|c|c|c|}
\hline Test conditions & PU - & PU - & PC MFI & PC MFI \\
\hline (frequency - Contact force) & Wheel 2 & Wheel 5 & $11.2 \mathrm{~g}$ & $32 \mathrm{~g}$ \\
\hline 12 Hours: $5 \mathrm{~Hz}-20 \mathrm{~N}$ & W1 & W2 & W3 & W4 \\
\hline 12 Hours: $10 \mathrm{~Hz}-30 \mathrm{~N}$ & W5 & W6 & W7 & W8 \\
\hline
\end{tabular}

Polycarbonate materials presented the best candidate for replacing polyurethane wheels, allowing the following wear tests schedule to be developed:

\subsection{Pin and samples preparation}

\subsubsection{Pin preparation}

The test pins are formed using grind materials received from CK Polymers in the case of the recycled plastics, and from two of the sample wheels collected (wheels 2 and 5). A mould is developed to form the pins, these are then injection moulded separately at the appropriate processing temperature for each material. Once the plastics are cured and the block has cooled, the pieces are removed from the mould and are ready to be cut into the desired length. This operation is done in two steps. Firstly, pieces are cut using a vertical saw; a lathe is then used to obtain a smooth surface.

\subsubsection{Sample preparation}

The sample was prepared from asphalt as used in many skate parks, pavements and road surfaces. Initial attempts at using a concrete sample met with mixed results due to excessive smoothing and sample degradation during the tests.

\section{Results and discussion}

\subsection{Friction results}

Typical data collected from the friction and wear tests is presented below:

\section{Friction coeff. VS time $-5 \mathrm{~Hz}$ and $20 \mathrm{~N}$}

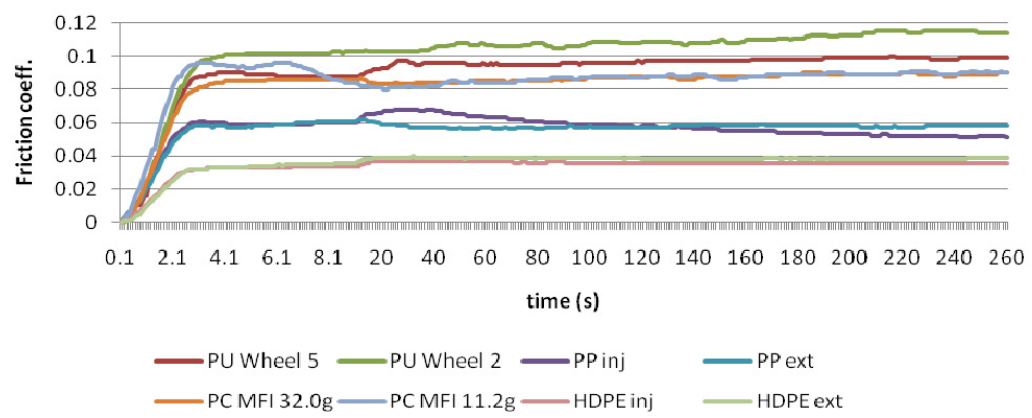

Figure 3: Friction coefficient versus time comparison. Contact force $20 \mathrm{~N}$, frequency $5 \mathrm{~Hz}$. 
In order to collate the data a mean value for the coefficient of friction is calculated from the stable friction portion of each materials test. The table below shows the results for the tests at $5 \mathrm{~Hz}$ :

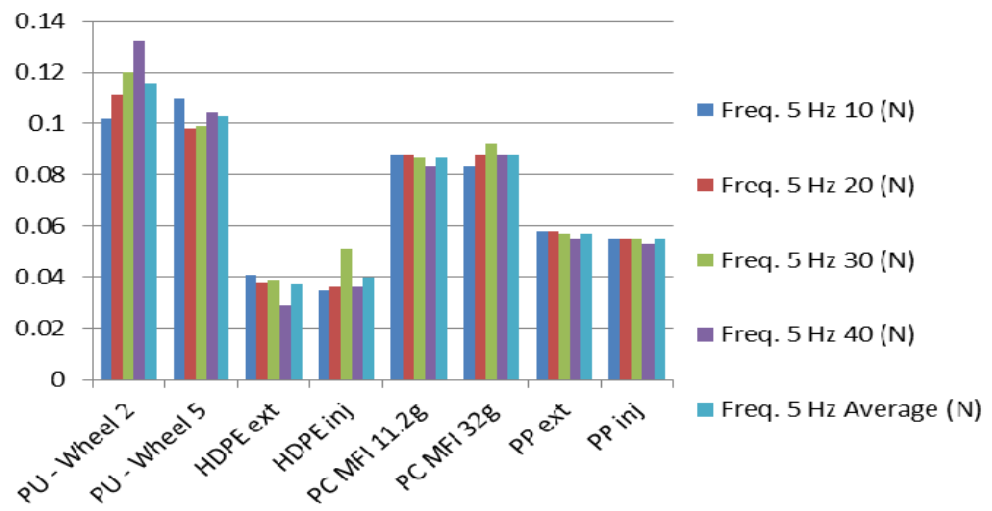

Figure 4: $\quad$ Frequency $5 \mathrm{~Hz}$. Friction test results.

From the tests conducted at $5 \mathrm{~Hz}$ frequency, it is found that the highest coefficient of friction recorded corresponded to the two PU wheel materials. Under the conditions tested, these materials show mean friction coefficients of $0.10-0.13$. Both PC grades present slightly lower friction coefficients of 0.08 0.09 , while extrusion and injection grades of PP present almost identical friction values of 0.055 . The two HDPE grades show very low coefficients of friction, between $0.029-0.05$. At the higher frequency of $20 \mathrm{~Hz}, \mathrm{PU}$ from wheel 2 presents the highest friction values. The hardest polyurethane, which was from wheel 5, gives lower values than the softer one from wheel 2. Under these conditions, both grades of polycarbonate and the extrusion grade of polypropylene show acceptable values of coefficient of friction for the desired application, giving results similar to PU wheel 5. Conversely, friction coefficients from HDPE and $\mathrm{PP}$ injection are again very low.

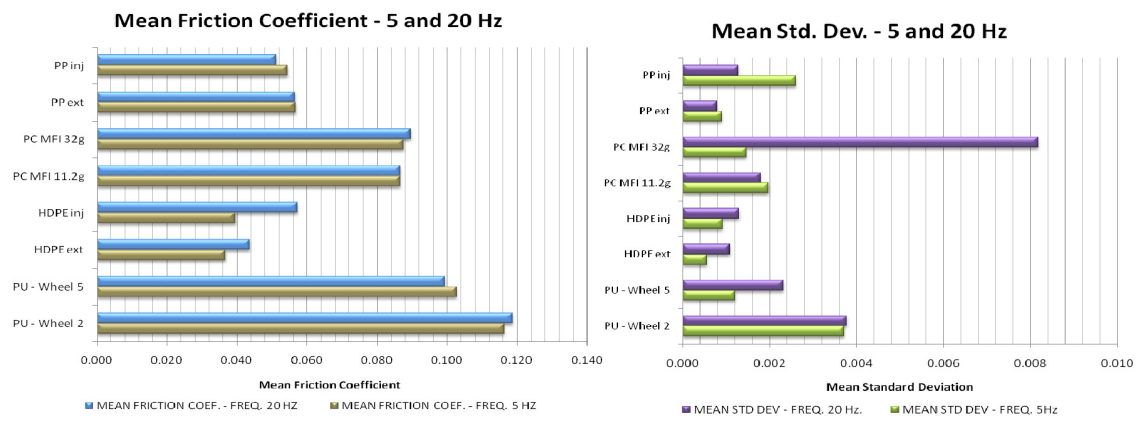

Figure 5: $\quad$ Mean friction coefficient and Standard Deviation for all materials 5 and $20 \mathrm{~Hz}$. 
Mean values of friction and standard deviation indicate that stable friction has been achieved. This indicates that no significant changes are seen through varying test conditions, indicating the grip between the wheel and pavement would remain consistent, as it is desirable for this application.

\subsubsection{Identification of contact mechanisms}

It is shown that cohesive wear mechanisms dominate when comparing the friction force proportionality to the applied load. If this is found to be proportionality to $\mathrm{W}$ then abrasive mechanisms dominate, while if it is found to be proportional to $\mathrm{W}^{1 / 3}$ then adhesive mechanisms will dominate. [22]
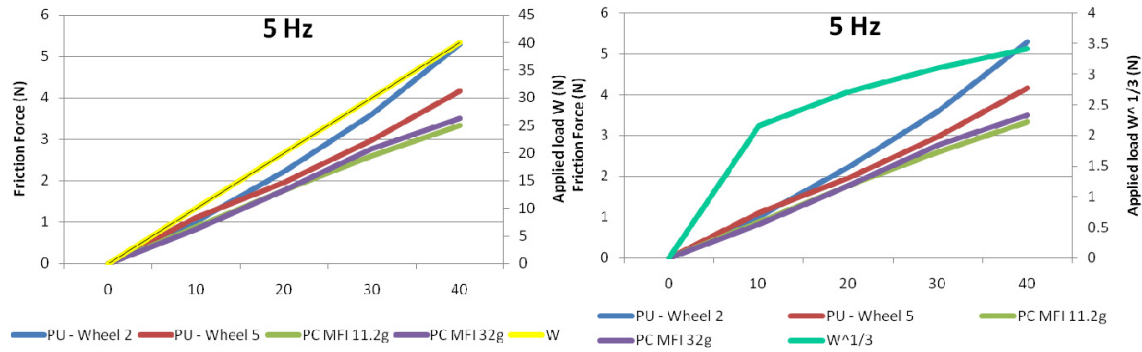

Figure 6: $\quad$ Friction force proportional to contact load $\mathrm{W}^{1 / 3}$.

The graphs show a direct correlation between the friction force and the applied load $\mathrm{W}$, indicating that cohesive, abrasive contact mechanisms are present. Contact test results vs. $\mathrm{W}^{1 / 3}$ are also shown, the lack of correlation implies that adhesive contact mechanisms were absent.

\subsection{Sliding wear results}

For the sliding wear tests the pin mass is measured before and after the test to evaluate mass loss. The wear coefficient is then calculated using the equation: $W$ $=k F L=k F v t$, where $W$ is the wear volume $(\mathrm{mm} 3), k$ is the wear factor $(\mathrm{mm} 3 / \mathrm{Nm}) 10^{-8}, F$ is the contact force $(\mathrm{N}), v$ is the velocity $(\mathrm{m} / \mathrm{s})$, and $t$ is the elapsed time (s) [23]. The values for the wear coefficient $\mathrm{k}$, after running the each test for 12 hours are shown below:

Table 5: $\quad$ Wear coefficient results from extended wear tests.

\begin{tabular}{|c|c|c|c|c|}
\cline { 2 - 5 } \multicolumn{1}{c|}{} & \multicolumn{4}{c|}{ Wear Coefficient $\mathbf{k},\left(\mathbf{m m}^{\mathbf{3}} \mathbf{N} \cdot \mathbf{m}\right) \cdot \mathbf{1 0}^{-8}$} \\
\cline { 2 - 5 } \multicolumn{1}{c|}{} & PU - Wheel 2 & PU - Wheel 5 & PC MFI 11.2g & PC MFI 32g \\
\hline 12 Hours: 5 Hz-20 N & $4.2 \cdot 10^{-4}$ & $2.3 \cdot 10^{-4}$ & $1.03 \cdot 10^{-4}$ & $2.72 \cdot 10^{-4}$ \\
\hline 12 Hours: 10 Hz-30 N & $4.14 \cdot 10^{-4}$ & $5.9 \cdot 10^{-5}$ & $2.12 \cdot 10^{-4}$ & $4.14 \cdot 10^{-4}$ \\
\hline
\end{tabular}

The surface of the pins was also scanned using an inferometer to understand the wear mechanisms present. These again indicated that the dominant mechanism acting was abrasive wear. In the inferometer images the surface is seen to present parallel grooves in the direction of sliding after running the tests. The surface roughness was also noted to increase. 
Table 6: $\quad$ Surface conditions and ZYGO data before and after wear tests for PU-Wheel 5 and PC MFI 11.2g.

\begin{tabular}{|c|c|c|c|c|}
\hline & \multicolumn{2}{|c|}{ POLYURETHANE WHEEL 5 } & \multicolumn{2}{c|}{ PC MFI 11.2 g } \\
\hline & Start - 0 hours & After 12 hours & Start - 0 hours & After 12 hours \\
\hline Ra & $4.289 \mu \mathrm{m}$ & $9.654 \mu \mathrm{m}$ & $1.985 \mu \mathrm{m}$ & $6.309 \mu \mathrm{m}$ \\
\hline Rrms & $5.192 \mu \mathrm{m}$ & $12.052 \mu \mathrm{m}$ & $2.391 \mu \mathrm{m}$ & $7.620 \mu \mathrm{m}$ \\
\hline PV & $17.735 \mu \mathrm{m}$ & $56.313 \mu \mathrm{m}$ & $11.527 \mu \mathrm{m}$ & $29.876 \mu \mathrm{m}$ \\
\hline Size X & $0.14 \mathrm{~mm}$ & $0.36 \mathrm{~mm}$ & $0.36 \mathrm{~mm}$ & $0.71 \mathrm{~mm}$ \\
\hline Size Y & $0.11 \mathrm{~mm}$ & $0.27 \mathrm{~mm}$ & $0.27 \mathrm{~mm}$ & $0.54 \mathrm{~mm}$ \\
\hline
\end{tabular}

\section{Conclusions}

\subsection{Friction tests results}

Tribometer friction results show that real-world PU wheels present friction coefficients between $0.1-0.15$, to present a viable alternative recycled plastics must approach these values. PC grades meet the friction specification, as friction coefficient values $(\mu \approx 0.09)$ are noted to be only slightly lower than that of harder PU grades. The other recycled plastics tested do not meet the friction specification exhibiting typical values of $0.04-0.05$. The tests show that the friction for each material remains stable, presenting consistent values across the tested conditions. This implies that the wheel will also exhibit stable performance, without significant changes across load and speed conditions that could make the skateboard uncontrollable. The friction tests also show that the friction force is proportional to the applied load $\mathrm{W}$, indicating that the contact mechanism is mainly cohesive and abrasive.

\subsection{Wear tests results}

Wear tests carried out for PU and PC show that the wear factor for these materials is similar, with no substantial difference between them that would preclude the use of $\mathrm{PC}$ for this application.

\section{Sustainability considerations}

With more than 50 million skateboard users worldwide [24] the quantity of wheels manufactured every year by skateboard industries is large. Skate wheels are also a high turnover product with skaters often upgrading their wheels regularly as they wear. Assuming that each skateboarder uses one set of wheels per year (4 wheels), this equates to 200 million wheels/year. Each set of wheels has an mean mass of $\sim 0.85 \mathrm{~kg}$, indicating $\sim 2,500$ tonnes of PU is used globally per year in skateboard wheel production. Using the CES material database software [25] this corresponds to 284.75 million $\mathrm{kg} \mathrm{CO}_{2} /$ year. 


\section{1 $\mathrm{CO}_{2}$ footprint and embodied energy}

Recycled plastics can be considered as waste that otherwise would have been sent to a landfill or heated for the recovery of energy, so the $\mathrm{CO}_{2}$ footprint from the primary production is not considered. The moulding $\mathrm{CO}_{2}$ footprint is included as this is the same for both PU and rGrade materials. All data was obtained from the CES 2010 EduPack [25]. If recycled plastics were used total $\mathrm{CO}_{2}$ footprint per wheel would be reduced by almost $50 \%$, from $6.7 \mathrm{~kg} \mathrm{CO} / \mathrm{kg}$ to $\sim 3.6 \mathrm{~kg} \mathrm{CO} / \mathrm{kg}$. If the 42,500 tonnes of $\mathrm{PU}$ employed here each year was replaced by one of the recycled plastics the $\mathrm{CO}_{2}$ footprint would be reduced to 148.75 million $\mathrm{kg} \mathrm{CO}_{2}$ /year, a saving of 136 million $\mathrm{kg} \mathrm{CO}_{2}$. According to the mean household carbon emissions [26] of 12.4 tonnes/year, the above savings would correspond to the annual emissions of around 11,000 households.

The embodied energy consumption is calculated as above, once again the energy consumed is substantially reduced when using recycled plastics, one $\mathrm{kg}$ of recycled plastics corresponds to $60 \%$ of the energy consumed for the same weight of PU. Considering the 42,500 tonnes/year polyurethane production, this would mean reducing the total energy consumption by up to $2,200 \cdot 10^{6} \mathrm{MJ} /$ year.
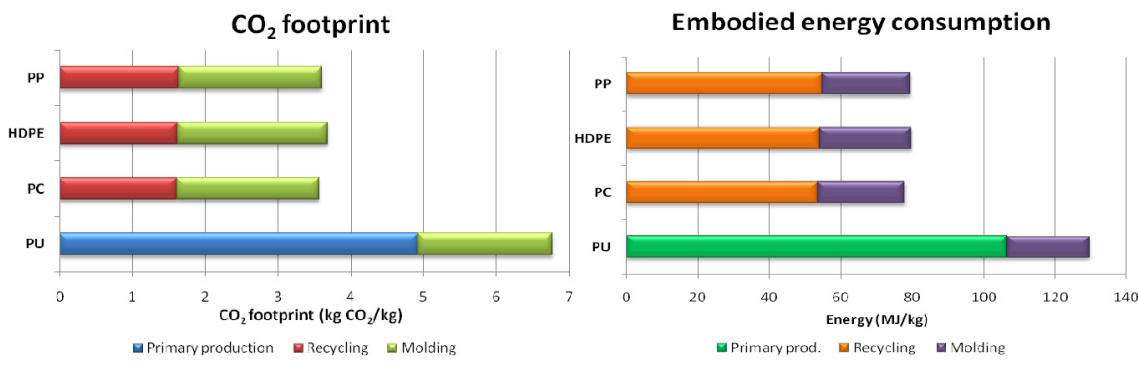

Figure 7: $\quad \mathrm{CO}_{2}$ footprint and embodied energy.

\subsection{Economic analysis}

Sustainability includes wider issues such as economic and social aspects, which combined with the environmental impacts represent the 'three pillars' of sustainability [27]. The cost of polyurethane is much more expensive than that of recycled plastics, especially the price for HDPE and polypropylene, which is almost 10 times smaller. The total annuals savings would represent many millions of pounds, depending on the material selected.

\subsection{Other considerations}

Even if further work advises against the use of polycarbonate to wholly replace polyurethane, recycled plastics could still be used in 'dual durometer wheels', wheels with an inner core made of a different material than the riding surface. Normally, the inner core is harder than the riding surface, i.e. $100 \mathrm{~A}$ vs. $95 \mathrm{~A}$. The inner core could be made of a recycled material while the riding surface 
could continue being made of PU, which would mean that the friction and wear rates continue unmodified, with all the environmental and economic benefits that the use of recycled plastics would involve. It may also be possible to incorporate friction modifiers into the recycled PP mix to bridge the $\sim 10 \%$ gap in friction that currently exists compared with PU.

Table 7: Costs of the different plastics materials - annuals costs and savings.

\begin{tabular}{|c|c|c|c|}
\hline & $\begin{array}{c}\text { Price } \\
(\mathfrak{f} / \mathbf{k g})\end{array}$ & $\begin{array}{c}\text { Total price } \\
(\text { millions of } £ / \text { year) }\end{array}$ & $\begin{array}{c}\text { Price } \\
\text { reduction }(\%)\end{array}$ \\
\hline PU & $3.3 £ / \mathrm{kg}$ & 140.3 & --- \\
\hline PC & $1.1 £ / \mathrm{kg}$ & 46.8 & $\approx \mathbf{6 7} \%$ \\
\hline HDPE & $0.44 £ / \mathrm{kg}$ & 18.7 & $\approx \mathbf{8 7} \%$ \\
\hline PP & $0.5 £ / \mathrm{kg}$ & 21.25 & $\approx \mathbf{8 5} \%$ \\
\hline
\end{tabular}

\subsection{Future work}

As polycarbonate seems to show good potential as a replacement for polyurethane, the next stage in this research would be to develop prototype wheels to test on real skateboards under real-life conditions. This would allow aspects other than friction and wear behaviour, e.g. rebound to be examined. It would also be interesting to test the potential application of recycled plastics in the hard inner core of the 'dual durometer wheels' as mentioned above.

\section{References}

[1] S. Stevens, E.: 'Green plastics: an introduction to the new science of biodegradable plastics', Princeton University Press, pp. 20-21 (2002).

[2] Borden, I.: 'Skateboarding, space and the city: architecture and the body', Berg, pp. 15- 19 (2001).

[3] Hasan, H.: 'Skateboarding Today and Tomorrow', Rosen, p18 (2009).

[4] Lawrence, C.: 'How skateboarding works' http://entertainment.how stuffworks.com/skateboarding4.htm, accessed 11/2011.

[5] Wanner, N.: 'The science and art of skateboard design' (2007) http://www.exploratorium.edu/skateboarding/skatedesignwheel.html, accessed 11/2011.

[6] V. Rosato, D.: 'Plastics Engineering, manufacturing and data handbook', Plastics Institute of America, Kluwer Academic Publishers, p180 (2001).

[7] Rigdon, M.: 'About the different types of skateboard wheels' http://www.ehow.com/about_4572409_different-types-skateboard-wheels. html, accessed 11/2011.

[8] Durometer: http://en.wikipedia.org/wiki/Shore_durometer, accessed $10 / 2011$.

[9] CCSi testing organization: www.ccsi-inc.com, accessed 02/2011.

[10] Polyurethanes.org: 'FAQs: What is polyurethane made of?', http://www.polyurethanes.org/index.php?page=faqs, accessed 12/2011. 
[11] Muccio, E.: 'Plastic part technology', ASM International, pp. 1-16 (1991).

[12] Goodship, V.: 'Introduction to plastics recycling', Smithers Rapra, pp. 5-6 (2007).

[13] Plastics 2020 challenge, The Questions: http://plastics2020challenge.com/, accessed 12/2011.

[14] Goodship, V.: 'Introduction to plastics recycling', Smithers Rapra, p131 (2007).

[15] La Mantia, F.: 'Handbook of plastics recycling', Rapra Technology, p-1 (2002).

[16] Grade Plastics: http://www.ckpolymers.co.uk/plastic-recyclingproducts.aspx, accessed 11/2011.

[17] Plastics in manufacturing: http:/www.wrap.org.uk/recycling_industry/ information_by_material/plastics/plastic_in.html, accessed 12/2011.

[18] YDNA Skate shop, Bournemouth.

[19] Plint, G.: 'Guidance notes on Choice of test machines', Phoenix-Tribology, (2003).

[20] Phoenix Tribology: Plint TE57 Product catalogue: http://www.phoenixtribology.com/, accessed 11/2011.

[21] Plint, G.: 'Guidance notes on Test specimens', Phoenix-Tribology (2006).

[22] Sinha, Sujeet, K: 'Wear Failures of Plastics' p1022, in 'ASM Handbook: Failure Analysis and Prevention Vol. 11: Failure Analysis and Prevention', ASM International (2002).

[23] Archard, J.F: 'Contact and Rubbing of Flat Surfaces'. Journal of Applied Physics 24(8) pp. 981-988 (1953).

[24] Hickok Sports: http://www.hickoksports.com/history/skateboarding.shtml, accessed 03/2011.

[25] Granta Design, CES 2010: http://www.grantadesign.com/products/ ces/overview.htm, accessed 11/2011.

[26] HCF: 'How do we contribute to global warming?', http://www.thehcf.org/ emaila5.html, accessed 03/2011

[27] Thomas, B.: 'Friction and wear performance of lifeboat launch slipways', Thesis (PhD), Bournemouth University (2009). 